\title{
Comprehensive Improvement Technology Research on Marine Shot Blasting Machine
}

\author{
Junlai LI ${ }^{12, a}$, Yonghe XIE ${ }^{1, b}$ \\ ${ }^{1}$ School of Naval Architecture and Ocean Engineering; Zhejiang Ocean University; Zhejiang \\ Zhoushan 316022; China; \\ ${ }^{2}$ School of Transportation; WUT; Hubei Wuhan 430063; China

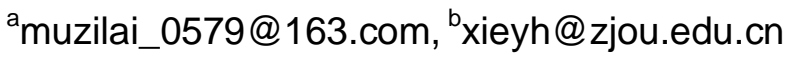

Keywords: Shot blasting machine; Impeller head; Pretreatment

Abstract: The number of impeller head is short in the original shot blasting machine, and the distance between the pretreatment of steel plate is too far to have enough rust removal ability. Based on these problems, researchers respectively added one impeller head both on the top and bottom of the machine, shortened the underside installation height, and adjusted the angle of impeller heads. The practice proved that the new improved shot blasting machine was satisfied with the requirement of the pretreatment.

\section{Introduction}

In recent years, China's shipbuilding technology has developed rapidly, and it is mainly due to improvement of shipbuilding equipments. Shot blasting machine is a kind of equipment which removes rust, residual slag and oxide on the surface of the steel by blasting method, and makes the steel surface to restore bright and clean ${ }^{[1]}$. The emergence of shot blasting machine has brought better conditions for shipbuilding. However, there are still some shortcomings and the insufficiency in the existing shot blasting machine, such as descaling effect being not very ideal, needing rework, delaying the shipbuilding period and so on. Based on the above reasons, comprehensive technical improvement research on marine shot blasting machine is very important.

\section{The Problems of Blasting}

Shot blasting machine is a continuous roller feeding high function shot blast cleaning equipment. By its around the face of different coordinates azimuth powerful dense bullets hit and the friction, make its scale, rust layer and its dirt falls off quickly, the steel surface becomes a bright and clean surface with certain roughness. ${ }^{[2]}$

Before ship construction, steel surface pretreatment should be according to the rules of the $\mathrm{CB} / \mathrm{T}$ 231-231 in 5.1. After the pretreatment, steel surface should be stipulated in GB/T 8923-1988 of $\mathrm{Sa} 2^{1 / 2}$ level, and its roughness should stay between $30 \mu \mathrm{m} \sim 75 \mu \mathrm{m}$ (according to $\mathrm{GB} / \mathrm{T}$ 13288-13288). Before improvement, due to the equipment aging, steel surface pretreatment could not reach the requirements of preprocessing, such as injection treatment can not reach the prescribed $\mathrm{Sa} 2^{1 / 2}$ level, roughness is larger than $80 \mu \mathrm{m}$, the surface of the steel remains solid oxide scale, rust, a small amount of steel shot after shot blasting treatment, dust cleaning is not up to standard and so on ${ }^{[2]}$. Because of profile in plate pretreatment line processing, the treatment effect of profile structure opposite is also very poor. By dismantling equipment, reseachers found that the original design of the impeller head in blasting machine shortage, far in the distance, the rust removal capacity to poorly spread out on both sides of the area. As shown in Fig.1.

Case 1: It can not meet the visual demand such as a small amount of residual steel shot still remain on the steel surface after shot blasting treatment,dust cleanliness be not up to standard, the sand be inclusion in the paint film after processing etc.... 
Case 2: Steel after surface blasting treatment still remain solid oxide scale and rust, especially treatment effect to the surface under sheet metal surface or to the opposite surface of profile structure is very poor.

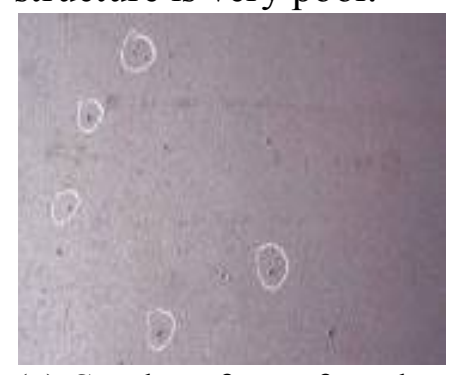

(a) Steel surface after shot blasting

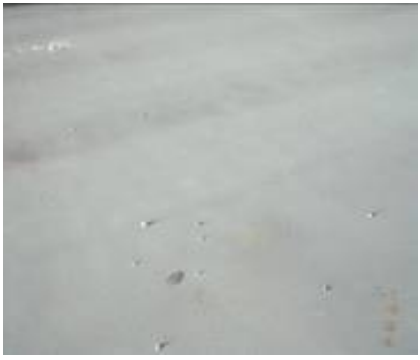

(b) Steel surface after spray paint

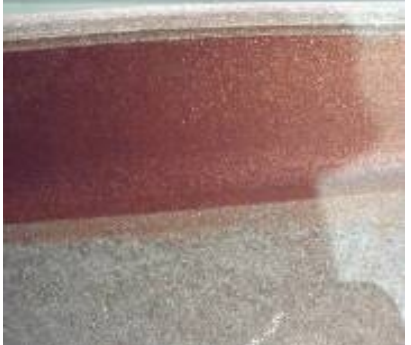

(c) Opposite surface to the section bar after shot blasting

Fig. 1 The pretreatment effect of original shot blasting machine

\section{Improvement Techniques to Shot Blasting Machine}

At present, the shot blasting machine has been improved to 4.5 meter type and 3.2 meter type(4.5 meter shot blasting machine for DESAT20, and 3.2 meter model for DESA600). In order to make the steel surface treatment to achieve $\mathrm{Sa} 2^{1 / 2}$ level requirement, various parameters(the impeller head shot angle, distance, quantity,etc.)

need been studied at first, and then the relationship between these parameters and the speed of steel moving needs been improved.

For the renovation of 4.5 meter shot blasting machine adopts the direct connecting ac power source type, it can improve the efficiency of the shot blasting machine or reduce the belt drive power loss. For the reconstruction of the 3.2 meter shot blasting machine adopts dislocation type ac power form, it can reduce the power loss of the motor, raise the working efficiency and eliminate the correlation field rate all safe operation.

By optimizing the modification, the assembly line can be added a shot blasting machine. It can increase the effective working face cross area and ensure the descaling effect between shot blasting machine. After optimization, two shot blasting machine installation angle adjustment for 10 degrees to each side, so that it can ensure the cleaning effect of steel plate edge. As shown in Fig. 2 and Tab.1.

The shot blasting machine under the steel plate, not only did the same modifications above, but also reduced the distance of shot blasting machine and steel from $900 \mathrm{~mm}$ to $820 \mathrm{~mm}$. So that it can eliminate the effects of gravity.

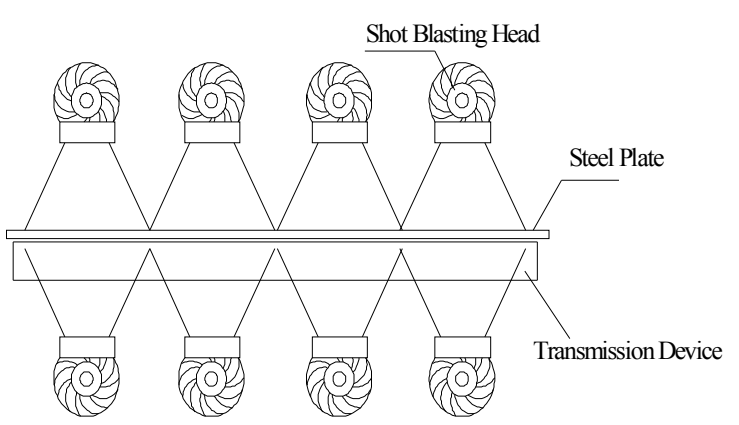

(a) Before optimization

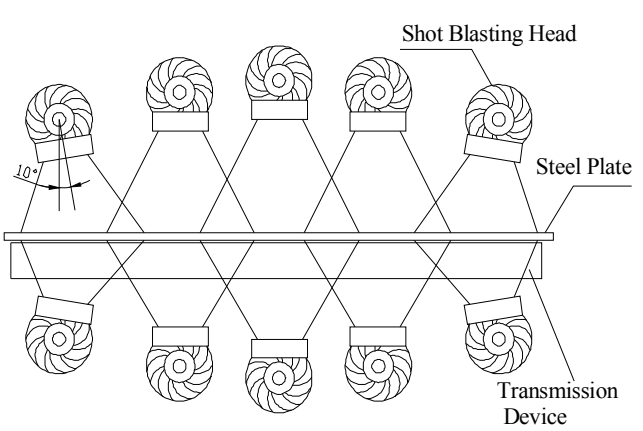

(b) After optimization

Fig. 2 The layout of the shot blasting machine 
Tab.1 Parameters to Improve

\begin{tabular}{ccc}
\hline & \multicolumn{2}{c}{ Equipment improvement } \\
\cline { 2 - 3 } & Before & After \\
\hline The projectile Angle on both sides $\left({ }^{\circ}\right)$ & 90 & 100 \\
$\begin{array}{c}\text { The distance from shot blasting head } \\
\text { underside to steel plate (mm) }\end{array}$ & 900 & 820 \\
$\begin{array}{c}\text { The number of shot blasting heads } \\
\text { upper and underside }\end{array}$ & 4 & 5 \\
\hline
\end{tabular}

\section{Technology 1:Impeller Head's Parameters Optimization.}

Different types of shot blasting machine have multiple impeller heads. In order to improve the speed and quality of blasting, shot blasting machine increases the number of impeller heads in the pretreatment work. Each the ammeter reading of impeller heads can display the working condition of each shot blasting machine. The improved shot blasting machine is available in the direct connection between nozzles, which Angle depending on the actual installation and handling requirements. The machine's cleaning unit should be able to cover the whole steel plate, its spacing should be kept in $1.2 \mathrm{~m}$. In Normal work, the working current of 3.2 meters shot blasting machine is $45 \mathrm{~A}$, and the 4.5 meters's working current is $60 \mathrm{~A}$. Shot blasting machine's impeller speed is 2960rpm, resulting in a strong centrifugal force. The abrasive are thrown along the blade at up to $98 \mathrm{~m} / \mathrm{s}$ speed. Throwing abrasive formed a fan beam, directly hit the surface of steel plate. Each impeller head's amount of sand blasting is $200 \sim 250 \mathrm{~kg} / \mathrm{min}$.

For steel surface dust cleanliness effect being perfect, researchers make maintain effective clearance between rollers and steel plate, at the same time, adjust indoor blasting the angle of compressed air duct and distance from the steel plate. As shown in Fig.3.

\section{Technology2: Steel Plate Conveying Parameters Optimization.}

Steel plate conveying is performed by rollers. In order to ensure steel plate no deformation during blasting, the distance of the rollers should be different. Generally, rollers' distance is not greater than $500 \mathrm{~mm}$ in blasting indoor, and it could amplify appropriate to $600 \sim 800 \mathrm{~mm}$ when in front of the blast chamber. Steel plate conveying speed is usually associated with its original state. If the original state being grade A or B, the speed can be appropriately hurry, if encountering grade C steel with a few slight corrosion, transmission speed should be adjusted slightly slower. Transmission speed of the improved shot blasting machine is as follows: A/B grade steel speed on 4.5 meter type and 3.2 meter is $4.3 \sim 4.8 \mathrm{~m} / \mathrm{min}$, and grade $C$ steel remained at $3.2 \mathrm{~m} / \mathrm{min}$.

\section{Technology 3: Abrasive Parameters Optimization.}

The size of the steel plate surface roughness and rough shape are determined by Abrasive particle size, the present situation, material performance, function time ect.. In order to avoid the big roughness, the weight of an adding the new steel shot shall not exceed one third of the total weight in shot blasting machine.

In order to ensure the roughness in $30 \sim 75 \mu \mathrm{m}$, it must be strengthen abrasive incoming quality inspection of the factory at first to ensure the high quality abrasive and high cleanliness after processing. Secondly we need to adjust the size of the abrasive and composition, to adjust the air pressure and the current parameters of sand blasting, to control strictly the size of the abrasive and 
matching, to ensure that the sandblasting process parameters (such as current, air pressure etc..) are stable to meet the requirements of surface roughness in the whole process of using.

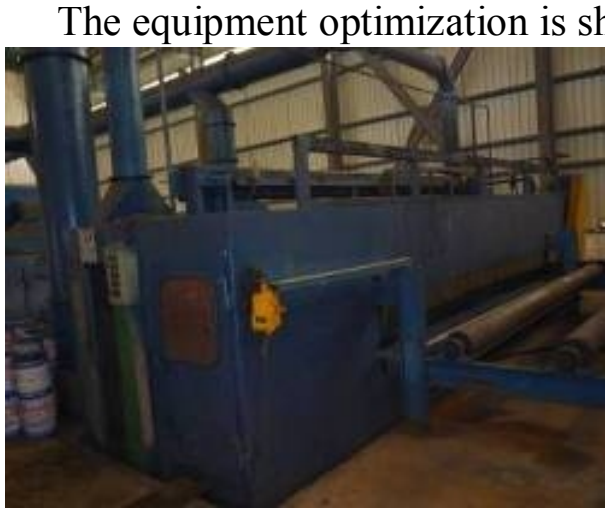

Fig.3 Shot blasting machine

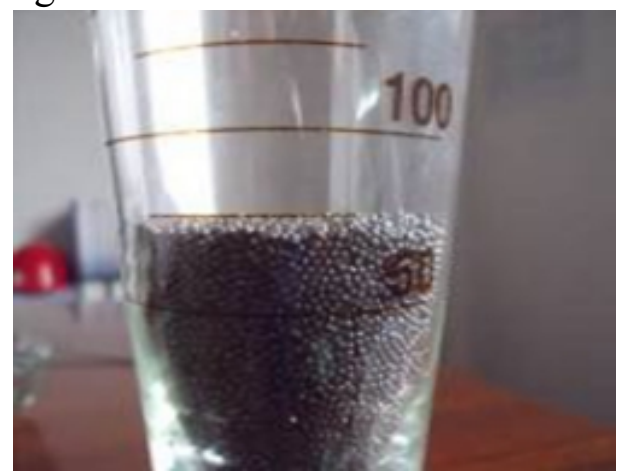

Fig.4 The specifications inspection of abrasive (steel shot)

\section{Improve Effect of Shot Blasting Machine}

Through the modification of shot blasting cleaning machine in pretreatment equipment, the article demonstrated the quantitative relationship between parameter requirements in the process of pretreatment equipment operation, established the numerical relations between the factors including the linkage between each nozzle form, the Angle of the nozzle, sprinkler spacing and speed of shot peening, different thickness of the plate $(6 \sim 40 \mathrm{~mm}$ steel plate thickness range)moving speed in pretreatment equipment, the types size of abrasive, and surface roughness of steel plate etc.. The reseachers did a lot of test, debugged the work schedule operation specification, and train the shipyard pretreatment line operators, make them strictly follow the operation specification requirement of reasonable construction operation, to ensure that reach the PSPC new rules on the steel surface treatment level and roughness index requirements. As shown in Fig.5, Fig.6 and Tab.2.

Tab.2 Steel Pretreatment Effect Comparison

\begin{tabular}{ccccc}
\hline \multirow{2}{*}{ Object } & \multicolumn{2}{c}{ Before optimization } & \multicolumn{2}{c}{ After optimization } \\
\cline { 2 - 5 } condition & Roughness & $\begin{array}{c}\text { Surface } \\
\text { condition }\end{array}$ & Roughness \\
\hline Steel plate & $\begin{array}{c}\text { Remain a small amount } \\
\text { of steel shot, with } \\
\text { obvious scale, rust, paint } \\
\text { coatings, etc.. } \\
\text { Leave a small amount of } \\
\text { Pteel shot, with obvious } \\
\text { scale, rust, dirt poor } \\
\text { cleanliness, etc.. }\end{array}$ & $55 \mu \mathrm{m}$ & No impurities, & $52 \mu \mathrm{m}$ \\
clean & $50 \mu \mathrm{m}$ & No impurities, & clean \\
$\begin{array}{c}\text { Demonstrating } \\
\text { compliance } \\
\text { (Yes Or No) }\end{array}$ & No & Yes & Yes & Yes \\
\hline
\end{tabular}




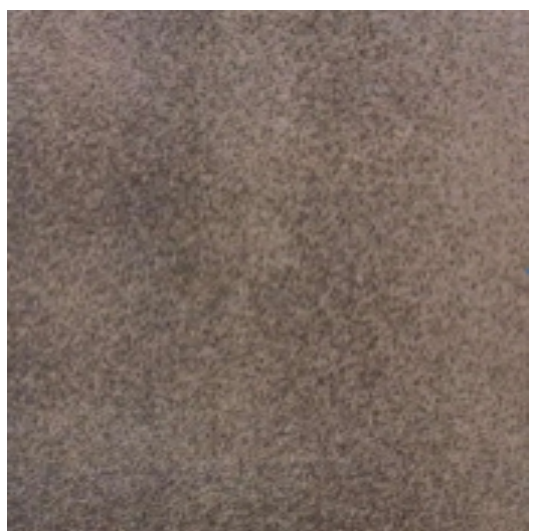

(a) before optimization

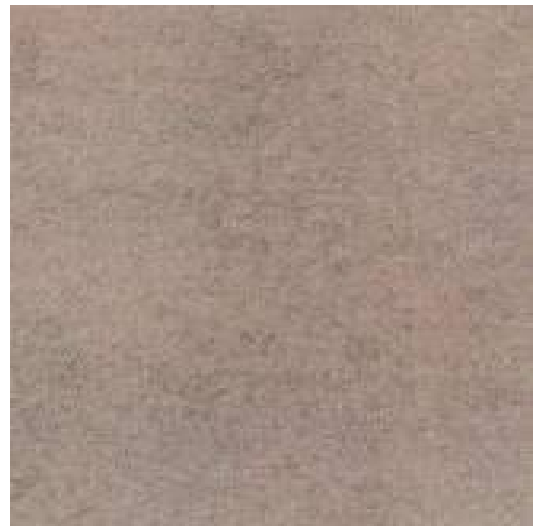

(b) after optimization

Fig.5 Steel plate processing effect comparison

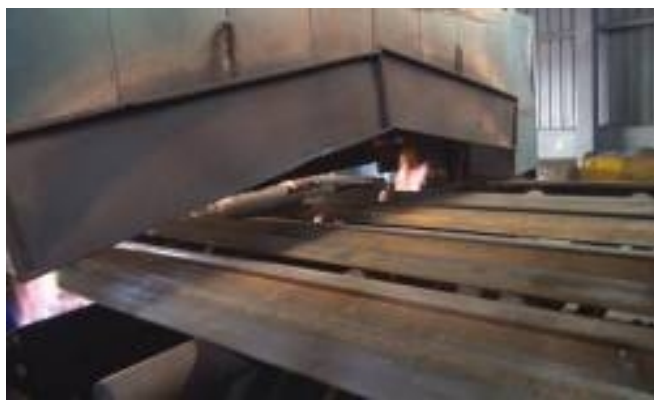

(a) Before optimization

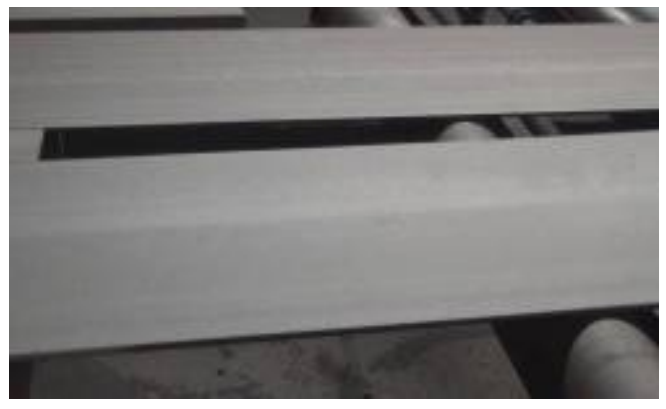

(b) After optimization

Fig.6 Profile processing effect comparison

By comparing the modification results of 4.5 meter and 3.2 meter shot blasting machine, it shows that improvement not only reduces the loss rate of the equipment, cuts the maintenance cost, improves the production effect of pretreatment line, but also reduces the maintenance works greatly. The improved shot blasting machine maintenance is convenient, it would provide quick maintenance and short the maintenance time, thus achieve the purpose of better service in production.

According to Tab.2 and Fig.8 10, without magnification to observe, surface grease and dirt can't be easy to find, and there is no scale, rust, paint coatings and other matter on its surface. The remaining traces is just a dot or stripes of slight discoloration. After pretreatment, steel surfaces can achieve GB/T8923-1988 $\left(\mathrm{Sa} 2^{1 / 2}\right)$,

and roughness can reach requirements (between $30 \mu \mathrm{m} \sim 75 \mu \mathrm{m}$ ).

\section{Summary}

The original shot blasting machine exist several disadvantages such as derusting incompletely,coverage width being not enough,etc. Based these problems, researchers respectively added an impeller head both on the top and bottom of the shot blasting machine, shorten the underside impeller head installation height, and adjusted the both sides of impeller head installed angle. Practice has proved that the improved shot blasting machine satisfies the requirement of the pretreatment of the steel plate.

\section{Acknowledgments}

We acknowledge the support of International S\&T Cooperation Program of China(Grant No.2012DFR80170). 


\section{Reference}

[1]Heping Tang. Shot Blasting Derusting Quality Control on Passenger Car Body[J]. Railway Operation Technology. Vol.12 No.4.2006.30-34. 'In Chinese'

[2]Baojin Ke.Artifacts Derusting Quality Factor Analysis and Prevention[J]. Railway Operation Technology. Vol.21 No.2.2015.4-6.'In Chinese' 